\title{
Research on the Spatial Characteristics and the Sustainable Development Strategies of Chinese Furniture Industry
}

\author{
Shiqing Yan \\ College of Urban and Planning, Yancheng Teachers University, Yancheng, China \\ Email:18360494968@163.com
}

How to cite this paper: Yan, S. Q. (2017). Research on the Spatial Characteristics and the Sustainable Development Strategies of Chinese Furniture Industry. Current Urban Studies, 5, 403-422. https://doi.org/10.4236/cus.2017.54023

Received: October 4, 2017

Accepted: November 28, 2017

Published: December 1, 2017

Copyright $\odot 2017$ by author and Scientific Research Publishing Inc. This work is licensed under the Creative Commons Attribution International License (CC BY 4.0).

http://creativecommons.org/licenses/by/4.0/

\section{(c) (i) Open Access}

\begin{abstract}
The overall spatial difference, the inter-regional and intra-regional spatial differences of the three regions-the eastern, central and western regions of Chinese furniture industry are obvious and constantly shrink. The number of population, the average consumption level of the residents, the added value of the secondary industry, the amount of foreign capital and the amount of furniture exports and other factors affect the furniture industry's spatial characteristics, but there are regional differences in the influence mechanism. In order to improve the industry development sustainably, it is necessary to optimize the division of furniture industry, focus on building cross-regional furniture industry chain, adopt advanced technology and equipment and strengthen the furniture brand construction. The eastern region should increase the technical input; the central region should pay more attention to market development, and the western region needs to strengthen industrial and financial support.
\end{abstract}

\section{Keywords}

Furniture Industry, Spatial Characteristics, Sustainable Development

\section{Introduction}

China is the largest furniture producer, exporter and consumer in the world. The development of the furniture industry has made an important influence on economic growth, labor employment and improvement of people's lives. Recent years, China's labor costs continue to rise, which causes the gradual loss of competitive advantage of the labor-intensive furniture manufacturing industry, the pace of furniture manufacturing enterprises transfer, from the eastern coastal 
areas to the central and western regions quickened and high attention paid on Chinese furniture industry spatial pattern and its changes by academia, politics and business. The furniture industry has gradually migrated from the eastern coastal areas to the central and western regions, and the central and western regions of the furniture market need to be further developed, and industry supporting conditions still need to improve, and in this context, how to give full play to the regional advantages according to the actual situation to improve the overall competitiveness of China's furniture industry is worth to discuss.

Since the reform and opening up, the development of private economy in the eastern coastal areas of China has promoted the development of furniture manufacturing industry. In order to save the labor cost, foreign furniture manufacturing enterprises have transferred the furniture manufacturing enterprises to Guangdong, Fujian and Zhejiang provinces in the southeastern coastal areas of China, which forms the inward and export production and management models (Wang, 2001). The above two kinds of business models have promoted the rapid development of the furniture manufacturing industry in the eastern coastal areas, and formed the spatial distribution pattern that furniture manufacturing industry is mainly concentrated in the southeast coastal areas, and few in the central and western regions (Chen, 2015; Zeng, Ma, \& Yang, 2015; Qin \& Zhao, 2010; Cheng, Jiang, \& Zhang, 2014). The cluster of furniture industry in China's eastern coastal areas is mainly based on low-level production factors, and the main feature of the elements structure is rich low-cost labor (Zeng \& Nie, 2012; Tian, 2006). However, the rapid development of the national economy and changes in social conditions forced the labor-intensive furniture manufacturing industry spatial pattern change; the furniture industry space transfer becomes inevitable (Sang, Zhang, \& Tian, 2016). China's furniture industry shows the characteristics of the stage in the process of space transfer. The first phase is internal industry development differences in East China and Central-south China caused the furniture industry transfer from a few furniture industry developed provinces to other provinces in the region. The second phase is regional differences in the development of furniture industry caused the cross-regional industrial proliferation and transfer from East China and Central-south China to the inland provinces (Shen, Qiu, \& Liu, 2016; Xu, 2016). The early space transfer of furniture industry is mainly to reduce labor costs. With the economic development of the central and western regions, the transfer of furniture enterprises can also open up the growing furniture market in the central and western regions (Zeng \& Nie, 2012). The industry space transferred from the southeast coastal areas to the western inland makes the gradual changes of China's furniture spatial pattern, which is of great importance to form the final formation of a relatively reasonable and balanced industrial space network (Zeng, Ma, \& Yang, 2015).

Owing to location factor, economic development and other factors, the regional differences of the international competitive forces in China's furniture industry are significant. Furniture enterprises in the southeast coastal areas not 
only take a leading position in the domestic furniture market, but also continue to explore the international market, both at home and abroad enjoying a relatively high reputation. Furniture enterprises in the central and western regions are short of brand awareness, not to achieve large-scale, intensive management (Gordan \& Martina, 2015). The analysis of Guangdong furniture industry competitive forces found that its furniture industry cluster has a certain competitive advantage in domestic market. But there is a large gap between the furniture manufacturing industry and the domestic industries with unique advantages in the local different industries. Inside of the industry, Guangdong furniture manufacturing industry has not yet formed a real international market influence (Li, 2015). Discovered by the study on the competitiveness of wood furniture, the factors influencing the international competitive forces of the furniture industry are: factor condition, related supporting industry and domestic demand and other factors (Zeng \& Nie, 2015). The research on furniture industry in different countries shows that the technological innovation is the key factor in the formation of international competitive forces of furniture industry rather than the advantage of labor endowment (Grzegorzewska \& Wieckowska, 2016; Feng, Cheng, \& Hao, 2011; Cheng, 2011). However, China’s furniture industry has formed a trade-oriented development model which neglects technology. Its technological progress is more of a new advanced equipment and new product imitation, short of independent innovation capability. Besides, the inertia of this development model is very large, it is difficult for the industry to achieve the coordinated development of trade and technology through its own internal changes (Wang, Zhang, \& Qiu, 2011). In addition, the competitive force of the furniture industry has a strong relevance with industrial space agglomeration (Lin, Dai, \& Yu, 2014; Bryson, Lanzillotti, \& Myerberg, 2003).

The above research has important theoretical significance to reveal the formation mechanism of China's furniture industry spatial structure, the characteristics of industrial transfer and its dynamic mechanism, the spatial difference of industrial competitive forces and its influencing factors. It is of great reference value to guide the healthy development of China's furniture industry. However, the spatial characteristic of industry is the spatial representation of industrial competition. The spatial pattern of industry is formed in the industrial competition and changes with the competition. The formation of any industrial spatial pattern is the result of its internal and external factors. According to the characteristics of industry, economic conditions, technical level, social conditions and other factors, it is essential to consider the characteristics of industrial spatial pattern changes and its formation mechanism comprehensively. We should analyze industrial competitiveness, based on accurate prediction of the trend of spatial pattern changes. With the increasing of consumption and wage level and the shortage of labor supply in China, the "duality" of furniture production and consumption has an important influence on the industrial spatial pattern. From the perspective of labor supply, the furniture production is characterized by both 
labor-intensive and technology-intensive industry, which reflects its "duality". Furniture production need to invest a lot of common labor, for labor-intensive industry; furniture design is inseparable from a good idea, for technology-intensive industry. The consumption of furniture has not only consumption features of both durable consumer, but also the consumption characteristics of fashion consumer goods, which is the "duality" feature. It takes many years for furniture from the purchase to the elimination, which is the reason why furniture is durable consumer goods. At the same time, furniture consumers often pay more attention to the function, design, color, style and other aspects of furniture, reflecting their preferences, values and aesthetic taste, which indicates that furniture consumption, has the characteristics of fashion consumer goods. To develop the strategy of enhancing the competitiveness of the industry, we must consider the "duality" characteristics of the furniture production and consumption industry and then analyze the changing trend of the spatial pattern and its formation mechanism.

Based on the analysis of Chinese furniture industry spatial pattern and its evolution characteristics, were veal its formation mechanism. On the basis of this, considering the "duality" characteristics of furniture production and consumption, the sustainable development strategy of Chinese furniture industry is explored according to the evolution trend of furniture industry spatial pattern and the economic and social factors that affect the furniture production in different regions.

\section{Methods and Data}

\subsection{Methods}

According to the furniture production in Chinese provincial administrative regions, the spatial characteristics and changes of the furniture industry are described by comparative concentration coefficient, variation coefficient and Theil index. We analyze the influence factors of the spatial characteristics and the mechanism of the furniture industry spatial characteristics and its changes in three regions in China by utilizing stepwise regression analysis, correlation analysis and qualitative analysis.

1) Comparative concentration coefficient. The comparative concentration coefficient is used to represent the dominance degree of an industry sector in an area, and the ratio of the share of output of the specific industry in the region occupies the whole country to the share of the region's GDP to the country.

$$
K_{j}=\frac{V_{j} / V}{G_{j} / G}
$$

where $K_{j}$ is the comparative concentration coefficient of furniture industry in $j$ province; $V_{j}$ is the furniture production in $j$ province; $V$ is the national furniture production; $G_{j}$ is the $j$ province's GDP; $G$ is the national GDP. This paper calculates the comparative concentration coefficient of furniture industry 
in 31 provinces in China from 2003 to 2012 respectively.

2) Variation coefficient. The variation coefficient is the ratio of the standard deviation to the mean, which indicates the dispersion degree of the statistics and has extensive comparability. This paper describes the differences of furniture industry in different regions in China by using variation coefficient quantitatively.

$$
C_{t}=\frac{\sqrt{\sum\left(V_{t j}-V_{t}\right)^{2} / n}}{V_{t}}
$$

where $C_{t}$ is the variation coefficient in the year of $t ; V_{t j}$ is the furniture production in $j$ province; $n$ is the number of provinces; $V_{t}$ is the average furniture production in each province in the year.

Theil index. The Theil index is an important indicator of the differences in economic and social development between regions, and can decompose the whole difference to different levels, which is not affected by the number of units studied. Therefore, we can compare the differences between regions. China's mainland 31 provinces can be divided into the eastern, the central and the western three regions. Among them, the eastern region includes 11 provinces including Liaoning, Hebei, Beijing, Tianjin, Shandong, Jiangsu, Shanghai, Zhejiang, Fujian, Guangdong and Hainan provinces. The central region includes Heilongjiang, Jilin, Shanxi, Henan, Anhui, Jiangxi, Hubei and Hunan. The western region includes 12 provinces including Chongqing, Sichuan, Yunnan, Guizhou, Guangxi, Tibet, Inner Mongolia, Shaanxi, Gansu, Ningxia, Qinghai, Xinjiang provinces. The furniture productions of each province from 2003 to 2012 as the indicators of furniture industry development, and the GDP values of these 31 provinces during 2003-2012 are selected as the indicators of economic development. As a result, the differences in the development of China's furniture industry are divided into the overall differences, inter-regional (East, Middle and West) differences and intra-regional (East, Central and West) differences. The Theil index is shown as below:

$$
\begin{gathered}
T=\sum_{i} \sum_{j} \frac{V_{i j}}{V} \ln \frac{V_{i j} / V}{G_{i j} / G} \\
T_{w}=\sum_{j} \frac{V_{i j}}{V_{i}} \ln \frac{V_{i j} / V_{i}}{G_{i j} / G} \\
T_{b}=\sum_{i} \frac{V_{i}}{V} \ln \frac{V_{i} / V}{G_{i} / G}
\end{gathered}
$$

where $T, T_{w}$ and $T_{b}$ represent the overall differences, inter-regional differences and intra-differences in China's 31 provinces, respectively; $V$ and $G$ represent the national furniture production and GDP; $V_{i}$ and $G_{i}$ represent the furniture production and GDP in the $i$ region; $V_{i j}$ and $G_{i j}$ represent the furniture production and GDP in the province of the $i$ region. 
In order to study the contribution of inter-regional differences and intra-regional differences to the overall differences in China's furniture industry, the inter-regional contribution rate and intra-regional contribution rate are calculated:

$$
\begin{aligned}
& \text { inter-regional contribution rate }=\frac{\text { inter-regional differences }\left(T_{b}\right)}{\text { overall differences }(T)} \times 100 \% \\
& \text { intra-regional contribution rate }=\frac{\text { intra-regional differences }\left(T_{w}\right)}{\text { overall differences }(T)} \times 100 \%
\end{aligned}
$$

\subsection{Data}

According to the availability principle, we select the furniture production of 31 provinces in China from 2003 to 2012, the economic and social development of each province, such as regional GDP, population, urbanization rate, the added value of each industry, regional total exports, completed area of residential, urban and rural resident incomes, the average consumption level of residents, total foreign investment, etc., as the data to analyze the spatial differences of furniture industry. Furniture production is from China Furniture Yearbook (2004-2013). The data of regional economic and social development is from China Statistical Yearbook (2004-2013). The statistics of China's furniture output value began in 2009, which lasted shorter. When conducting correlation analysis of furniture production and furniture output value in China, we found it is reasonable to analyze furniture production instead of furniture output value. Before or after the global financial crisis, the spatial characteristics of China's furniture industry changed gradually. In addition, the statistic caliber of China's furniture production changed in 2013. Thus, we selected the furniture production from 2003 to 2012 as an indicator of furniture industry development.

\section{The Spatial Characteristic and the Causes of Chinese Furniture Industry}

The spatial differences of China's furniture industry are obvious, not only for the nationwide differences, the inter-regional differences of the eastern region, the central and the western region, but also the intra-regional differences of each province is significant. In order to accurately characterize the spatial characteristics of China's furniture industry, based on the furniture production, the comparative concentration coefficient, the variation coefficient and the Theil index, this paper conducts dynamic analysis, from the three levels: overall differences, inter-regional differences and intra-regional differences. In addition, we analyze factors and cause of formation of features.

\subsection{The Spatial Characteristics of Chinese Furniture Industry}

The comparative concentration coefficient of furniture production can reflect the spatial concentration degree of Chinese furniture industry, and the Theil in- 
dex and variation coefficient can reflect the spatial difference. Thus, this paper describes the spatial characteristics of Chinese furniture industry with the above three indicators.

The overall spatial difference of Chinese furniture industry is obvious, but it is decreasing gradually. From 2003 to 2012, the comparative concentration coefficient, the variation coefficient and the Theil index can reflect the spatial differences and its changes. China's furniture industry is mainly concentrated in the eastern coastal areas of Guangdong, Fujian, Zhejiang, Shandong and other provinces. In 2003, the industry comparative concentrated coefficient in the Fujian Province was 6.69, Guangdong was 3.02, Zhejiang was 2.50, while Shaanxi was 0.03, Yunnan and Tibet were 0.02, Qinghai and Inner Mongolia were 0.01. In 2012, the industry comparative concentrated coefficient of the Fujian Province was 4.34, Zhejiang was 4.12, Guangdong was 1.75, while Yunnan and Gansu were 0.01 , Tibet was 0.004 , and Qinghai was only 0.0016 (Figure 1 ).

The overall spatial difference of Chinese furniture industry is gradually narrowing. In 2003, the variation coefficient of China's furniture industry was 2 . 4603 , increased to 2.7662 in 2004 , and then gradually declined in the volatility. In 2012, it dropped to 2. 0265 . The Theil index of China's furniture industry was 0.3523 in 2003, increased to 0.3687 in 2004 , and then fluctuated down to 0.2539 in 2012. Of course, the national Theil index is always greater than the inter-regional and intra-regional index of the eastern, the central and the western regions, indicating that the overall difference in China's furniture industry is greater than the differences (Figure 2).

The inter-regional differences of Chinese furniture industry are obvious, but it is in the shrinking. There were significant inter-regional differences in furniture production among the eastern, the central and the western regions. In 2003, the comparative concentration coefficient of the furniture industry in the eastern area was 1.54, 0.18 in the central region and 0.09 in the western region. In 2012, the comparative concentration coefficient of the three regions was 1.43, 0.40 and 0.16 respectively (Figure 1 ). The inter-regional differences are shrinking. From 2003 to 2012, the inter-regional Theil index increased slightly in 2004, and declined slowly in the rest years. The index in 2003 was 0.1396 , decreased to 0.1484 in 2004, and then gradually declined to 0.0971 in 2012. This shows that the inter-regional differences of the furniture industry in the three regions exist, and is gradually narrowing (Figure 2 ).

The changes of the intra-regional differences of Chinese furniture industry are complex. There were significant intra-regional differences in the furniture industry in the eastern, the central and the western regions. In 2003, the comparative concentration coefficient of furniture industry in Fujian Province was 6.69, 3.02 in Guangdong Province, and 2.50 in Zhejiang Province. However, Hebei Province and Hainan Province are in the eastern region, whose coefficient was only 0.34 and 0.74 respectively. The central region is also the case. The comparative concentration coefficient is 0.43 in Heilongjiang Province, 0.23 in Hubei 

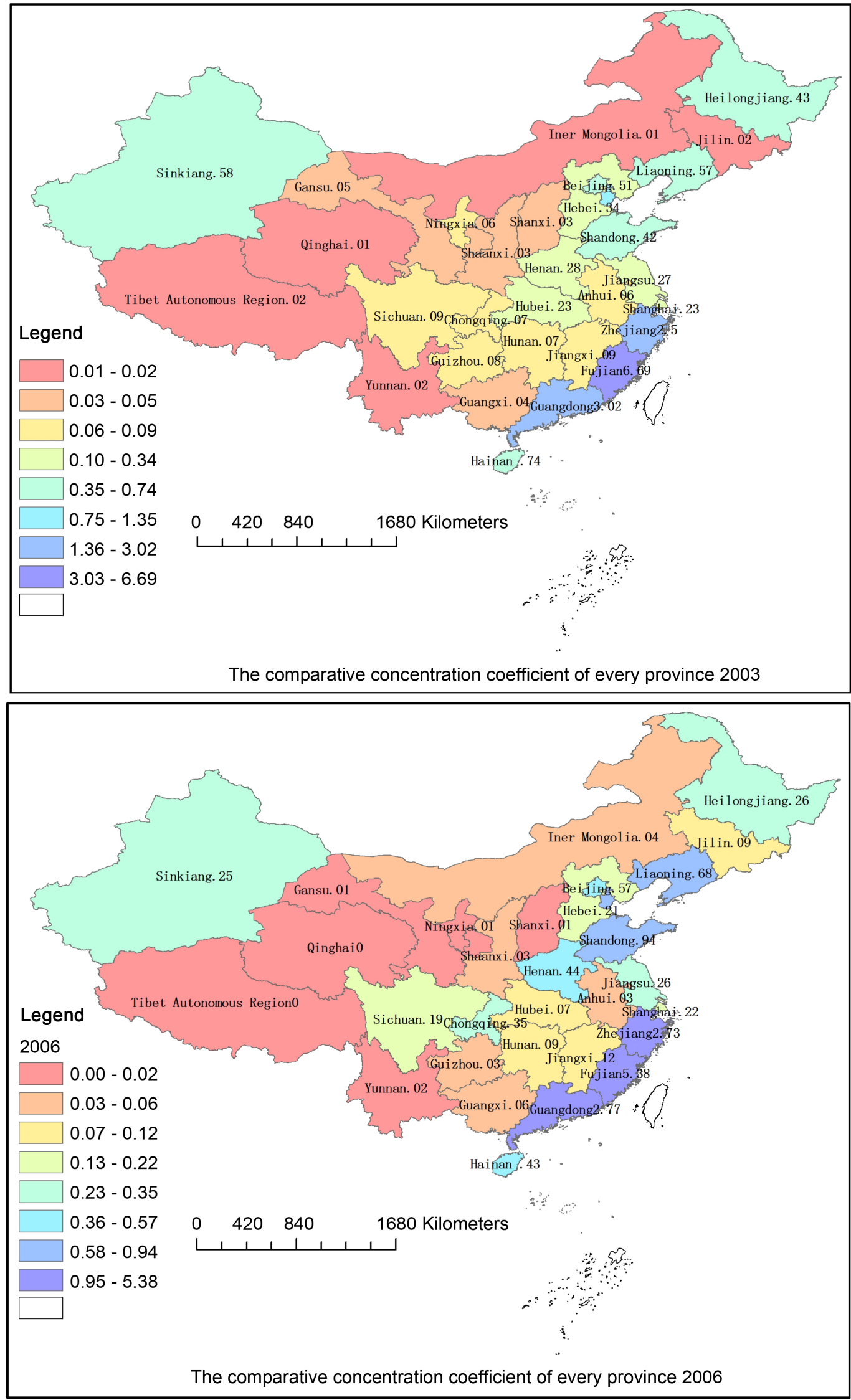

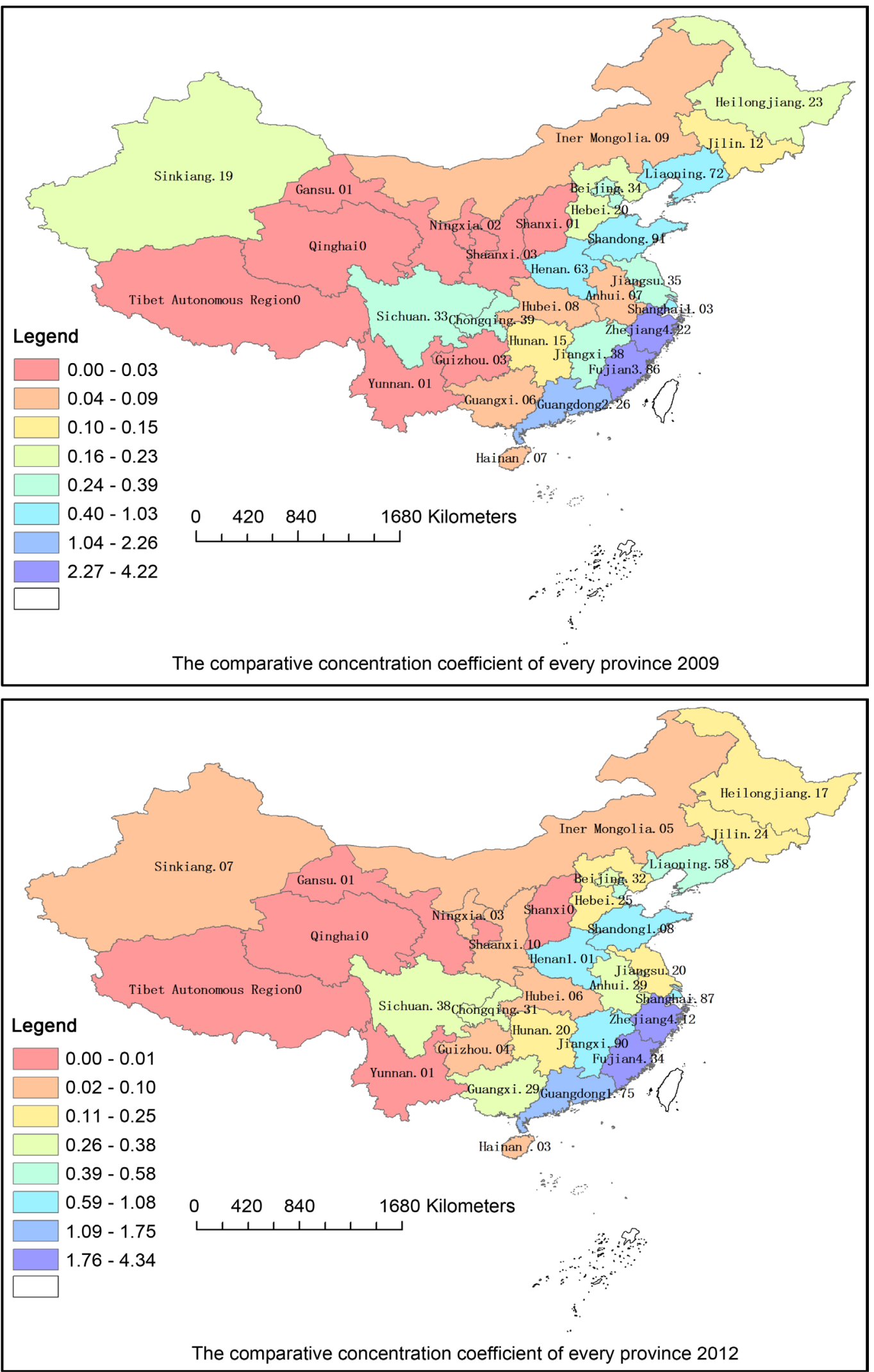

Figure 1. The comparative concentration coefficient of the Chinese furniture industry in 2003, 2006, 2009 and 2012. 


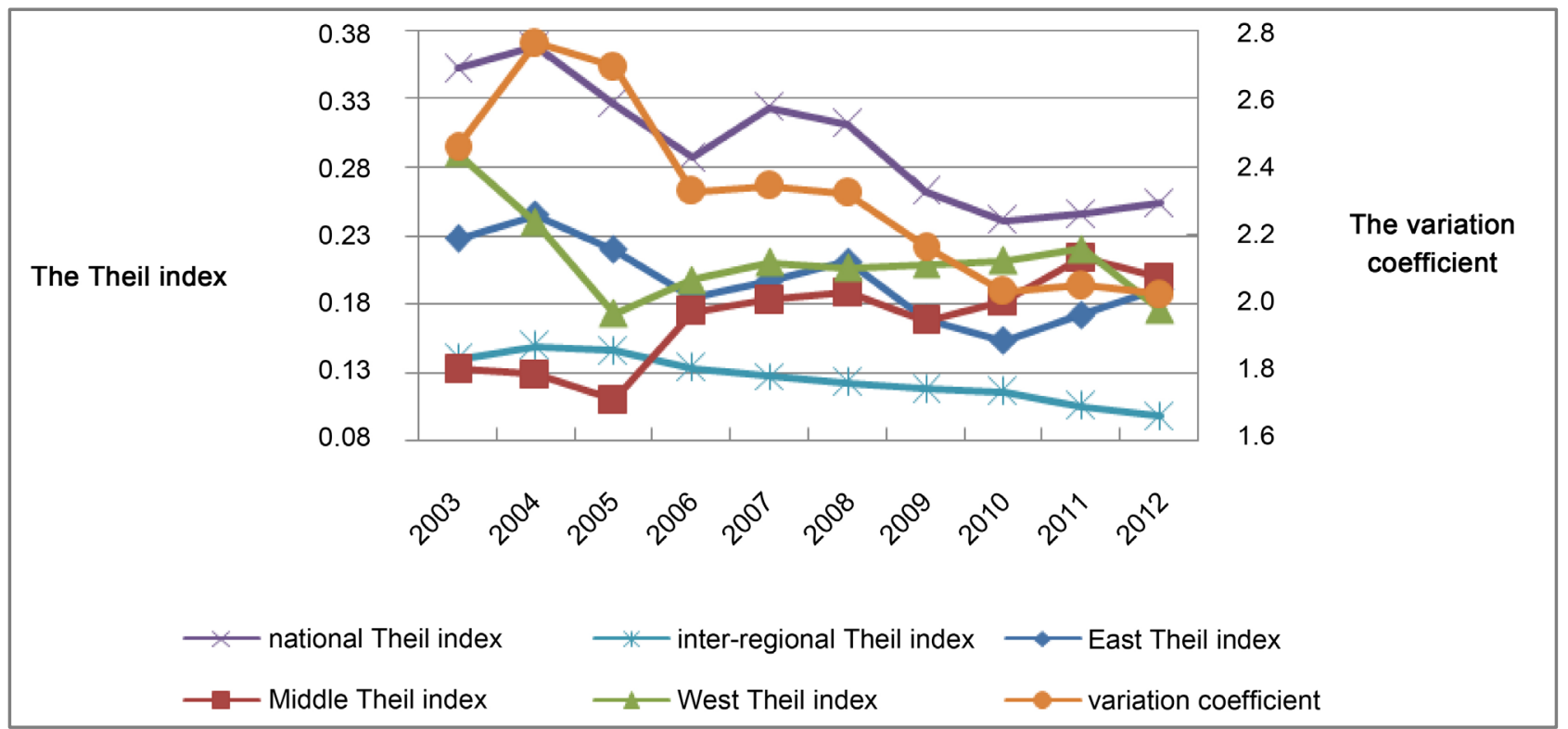

Figure 2. The Theil index and the variation coefficient of the industry from 2003 to 2012.

Province, while it is only 0.02 in Jilin Province and 0.03 in Shanxi Province. The western region of Xinjiang Autonomous Region is 0.58, Qinghai Province is only 0.01 (Figure 1). The differences of the comparative concentration coefficient of furniture industry in a region are significant, indicating striking intra-regional difference. It is complex for the changes of the intra-regional differences of Chinese furniture industry in the eastern, the central and the western regions. The intra-regional Theil index of the eastern region was 0.227 in 2003, and rose to 0.2449 in 2004 . Then the index decreased in volatility. It fell to 0.1720 in 2011, and increased to 0.1907 in 2012 slightly. The intra-regional Theil index of the central region increased significantly in the volatility. The index of the central region in 2003 was 0.1322 , after three plummets and two rises, it reached 0.1991 in 2012. The index of the western region quickly shrinks, and then fluctuated on high level, and dropped finally. The intra-regional Theil index of the western region was 0.2904 in 2003, and then dropped to 0.2399 in 2004. After dropping to 0.1728 in 2005 , it began to fluctuate on high level and finally dropped to 0.1756 in 2012 (Figure 2).

\subsection{The Causes of the Spatial Characteristics of Chinese Furniture Industry}

The domestic economic and social conditions have an important impact on the spatial characteristics of the furniture industry. In order to analyze the influence of domestic economic regional differences on the spatial differences of the industry, the relationship between furniture production and economic factors in the three regions was explored by stepwise regression analysis. First of all, we conducted correlation analysis of provinces the furniture production $(y)$ with a number of indicators of economic and social related analysis, and got seven re- 
levant indicators. They are population $x_{1}$, regional GDP $x_{2}$, the added value of secondary industry $x_{3}$, regional total exports $x_{4}$, completed area of residential $x_{5}$, the average consumption level of residents $x_{6}$, total foreign investment $x_{7}$. After these seven indexes were standardized, we analyzed the total output of furniture in the three regions and these seven indexes by stepwise regression analysis. The three linear regression equations were obtained (Table 1).

According to these regression equations, the differences of these three regional economic and social conditions affect the different independent variables and causes affecting the production of furniture. In the eastern region, population $x_{1}$ and the average consumption level of residents $x_{6}$ are two main influence factors of the furniture production. Furniture production $y$ is directly proportional to population $x_{1}$. The high level economy in the eastern region bring out the fashion consumption characteristics of furniture, and the short furniture update cycle make the impact of population on furniture consumption significant, which is the economic meaning. Furniture production $y$ is inversely proportional to the average consumption level of residents $x_{6}$, indicating that the higher per capita consumption level in the eastern region enhanced the local wage level, blocking the development of the labor-intensive furniture manufacturing industry. With the increase of the average consumption level of residents and wage level, the furniture industry will be forced to transfer to outside of the region. That is the reason why the proportion of furniture production in the eastern coastal areas and the comparative concentration coefficient declined in recent years.

In the central region, the average consumption level of residents $x_{6}$ was the only independent variable affecting the furniture production. The furniture production was directly proportional to the average consumption level of residents, indicating that the level of economic development and the associated per capita consumption level are relatively low in the central region, which brings out the obvious durable consumer goods characteristics of furniture. With the increase of the level of economic development and the level of per capita consumption, there are more consumers pursue fashion consumption in the process of furniture consumption, accelerating the update speed, increasing market demand and promoting the development of the furniture industry. In recent years, the rapid development of regional economy is the reason why the furniture production of Henan, Anhui, Jiangxi and other provinces in the central region grows rapidly.

In the western region, the added value of secondary industry $x_{3}$, regional total

Table 1. The regression equations of furniture production in the three regions.

\begin{tabular}{cccc}
\hline Region & Equation & Adjusted $\mathrm{R}^{2}$ & D.W. \\
\hline East & $y=2.807 x_{1}-1.887 x_{6}+1.018 \times 10^{-13}$ & 0.981 & 1.403 \\
Middle & $y=0.996 x_{6}+1.051 \times 10^{-13}$ & 0.991 & 2.334 \\
West & $y=1.676 x_{3}-0.857 x_{4}+0.170 x_{7}-1.002 \times 10^{-13}$ & 0.987 & 2.253 \\
\hline
\end{tabular}


exports $x_{4}$ and total foreign investment $x_{7}$ are the main variables affecting the furniture output $y$. The regional furniture production was directly proportional to the added value of secondary industry and total foreign investment. With the lowest degree of industrialization and weak furniture manufacturing industry supporting industry, the rapid industrialization of furniture manufacturing industry provides a better industry support to promote the development of the furniture industry in the western region. The added value of the secondary industry and total foreign investment are the important indicators to measure the degree of industrialization. The increase of these two indicators is bound to provide more favorable conditions for the development of the regional furniture industry. That is the reason why the proportion of the furniture production and the comparative concentration coefficient increase in the western region. The regional furniture production $y$ is inversely proportional to regional total exports $x_{4}$, which contains a specific economic meaning: the comparative concentration coefficient in the western region is small (Figure 1) and the furniture industry does not have advantages compared with other industries in the region. Due to the development of other industries, the exports of furniture in the western region increased. In other words, the competitive industries restrict the development of the furniture industry in the western region.

The impact of furniture exports on the spatial differences of furniture industry. China is a major furniture exporter, so the volatility of international market has impact on the spatial differences of furniture industry. By the analysis of national Theil index and the comparative concentration coefficient, we can describe the impact.

The Pearson and the Spearman correlation coefficient of furniture exports and variation coefficient from 2003 to 2012 were -0.856 and -0.927 respectively. From 2003 to 2012, the Pearson and the Spearman correlation coefficient of furniture exports and the Theil index were -0.841 and -0.879 respectively (Figure 2 ). It can be seen that there is a significant negative correlation between the furniture exports and its parts and the variation coefficient and the Theil index. When furniture exports increases, the variation coefficient and the Theil index of furniture industry decrease, and when furniture exports decreases, the variation coefficient and the Theil index of furniture industry increase.

Indeed, Chinese furniture exports was blocked, and the variation coefficient and the Theil index of furniture exports increased from 2006 to 2008 by the Global Financial Crisis originated in United States subprime mortgage crisis (Figure 2). From 2003 to 2005, the national Taylor index of furniture industry, the inter-regional Theil index and the intra-regional Theil index in the eastern, the central and the western regions showed a declining trend on the whole. Affected by the Global Financial Crisis, the Theil index of the furniture industry in the eastern region began to rise in 2007, and restored the level before the crisis in 2009. The Theil index in the central and the western region began to rise in 2006. Since then, the Theil index in the central region has been rising in the volatility. 
The Theil index in the western region, fluctuating on high level from 2007 to 2011, despite a more substantial decline in 2012, but still higher than the level before the financial crisis (Figure 2).

\subsection{The Causes of the Formation of the Spatial Characteristics of Chinese Furniture Industry}

The spatial differences of Chinese furniture industry are significant. The variation coefficient, the Theil index and the comparative concentration coefficient can describe its overall differences, inter-regional and intra-regional differences within the region, as well as changes of spatial differences. However, the cause of formation of spatial differences and changes is worth exploring.

1) The reason why Chinese furniture industry is concentrated in the eastern coastal provinces. According to the variation coefficient, the Theil index and the comparative concentration coefficient, Chinese furniture manufacturing industry is mainly concentrated in the eastern coastal areas, Guangdong, Fujian, Zhejiang and other provinces, which is related to the spatial differences of Chinese economic development, regional and social conditions. Low labor costs are one of the most important conditions for the eastern coastal areas to undertake overseas furniture industry transfer. China has the greatest population and the most abundant labor force. Chinese labor costs are much lower than those of Japan, Taiwan, Hong Kong, Macao and other East Asian countries in the early stage of reform and opening-up. It is inevitable that the labor-intensive furniture manufacturing industry transfers to China, with low labor cost.

The superior location conditions of the southeast coastal area make the transportation expense of furniture export and raw materials import inexpensive. The wood, plywood, hardware and other raw materials and accessories, as well as finished furniture, have the features of large-capacity and no time-demanding in the transport. The eastern coastal areas are close to large ports, providing cheap transportation expense of furniture export, which is a great attraction for the foreign furniture business.

The industrial support conditions in the eastern coastal areas have a great attraction for foreign furniture enterprises. After the reform and opening-up, China carries out the unbalanced development strategy, promoting the rapid development of the second and tertiary industries in the eastern coastal areas. The industries of furniture raw materials, accessories, furniture design and maintenance have developed rapidly. The development of related industries reduces the costs of transportation of raw materials and accessories, as well as the cost of purchasing raw materials and inter-firm cooperation.

The number of foreign investment in the eastern coastal areas is huge. After the reform and opening-up, with the rapid development of eastern China, foreign investors imitated others' investment strategy of investing in the eastern region, which is one of the main reasons. Guangdong, Fujian and other provinces are hometowns of overseas Chinese who are more willing to invest in their ho- 
metown, which is another important reason for the extensive use of foreign capital in the eastern coastal areas.

2) The reason why Chinese furniture industry transfer to the central and western region from the eastern coastal areas. The unbalanced development strategy implemented after the reform and opening-up is an important reason for the regional transfer of furniture industry. In the context of economic development from the eastern to the central and western regions, Chinese furniture industry gradually shifted from the eastern coastal areas to the central and western regions.

Economic development of the eastern region has raised the wage level, which is the strong driving force for the labor-intensive furniture industry transfer to the central and western regions. Since the reform and opening up, the wage gap between the eastern region and the central and western regions has changed greatly. The rapid rise of the wage level in the eastern developed areas is the most important reason for the industry transfer, which can be described by the results of the regression analysis of furniture production in the above to the less developed regions and the central and western regions.

The increase of furniture export volume has an important impact on the furniture industry transfer. Although the continuous improvement of Chinese eastern region's wage level has a certain negative impact on the international competitiveness of the industry, but the Chinese furniture is still highly competitive in the international market. The increase in furniture exports has pushed the industry transfer to the central and western regions. The empirical analysis above shows that the furniture export is strongly negatively correlated with the variation coefficient and the Theil index.

\section{Sustainable Development Strategies of Chinese Furniture Industry}

The spatial characteristic of industry is the spatial reflection of industrial competition. Strictly, the spatial characteristics are constantly changing, and the quantitative change leads to qualitative change. According to the spatial characteristics and its changing trend, the following strategies are proposed.

Firstly, the furniture industry should propose development strategy based on the furniture industry spatial pattern and its changing trends. The empirical evidence shows that the average consumption level of residents in the eastern region is negatively correlated to the output of the furniture in the eastern region. The continuous development of productivity and the improvement of the average level of consumption of residents is the historical necessity, which leads to continuously decline of furniture production and the spatial features of the industry change. Therefore, we should follow the develop trend of furniture industry, try to reduce the transfer resistance, optimize the regional division of labor and strengthen the construction of cross-regional furniture industry chain. Based on the force for the furniture industry transfer is the rise of wage level 
caused by the shortage of labor supply, we should take new technologies and new equipment to promote the change of furniture manufacturing industry from labor-intensive to technology-intensive, gain technical advantage and win the competition with Southeast Asian nations, who have cheap labor force, as soon as possible. We should strengthen the brand building of furniture, and construct the big furniture-producing nation and exporter as a powerful furniture brand nation.

Secondly, the eastern region should formulate new furniture industry development strategies in the background of regional furniture production reduce. The furniture production is characterized by both labor-intensive and technology-intensive industry, which reflects its "duality", but the progress of network technology has led to a decrease in the spatial dependence of labor-intensive furniture manufacturing and technology-intensive furniture design. Under the new situation of furniture manufacturing industry transfer to the central and western regions, the eastern region should focus on the ends of "the Smiling Curve", change the furniture industry's first mover advantage into technical advantages, increase the investment in furniture design and the manufacturing technology, provide intellectual support for the sustainable development of the industry. From the furniture consumption of both durables consumption and fashion consumption of the "duality" point of view, the higher the average level of consumption of residents and the obvious growth trend, promoting more consumers to follow the trend of consumption and personalized consumption, which reflects the characteristics of fashion consumption in the eastern region. Based on regional practice, the eastern region should gradually improve the production of high-grade, personalized furniture and promoted the sustainable development of furniture industry.

Thirdly, the relative advantages of furniture manufacturing in the central region appear gradually, and we need to vigorously develop the regional furniture market. Furniture production is proportional to the average consumption level of the residents in the central region. Obviously, the continuous development of regional economy and the increase of the average consumption level of the residents will expand the regional furniture market. The central region should focus on strengthening the development of regional furniture market while dealing with the relationship between the international market, the domestic market and regional market. Making full use of regional advantages to increase the regional market share, this region should expand the furniture production scale, reduce production costs through the scale effect and strengthen the international competitiveness of the furniture industry.

Fourthly, the western region needs to tap the potential of the development of furniture manufacturing industry. Empirical evidence shows that the furniture production of western region is proportional to the added value of the secondary industry and foreign investment. Thus, the western regions should focus on the development of the correlative industry and industry supporting, while under- 
taking the furniture industry transfer from the eastern region to the central and Western. In addition, we should optimize the investment environment and provide financial support for the development of furniture enterprises.

\section{Conclusions and Future Research Directions}

Through the analysis of the spatial characteristics and the sustainable development strategies of Chinese furniture industry, we draw the following conclusions and the future research directions.

\subsection{Conclusions}

Firstly, the spatial difference of Chinese furniture industry is obvious, but it is decreasing gradually these years, because the wage increases caused by the economic development and the shortage of labor supply have made the furniture manufactures in eastern region transfer to the central and the western regions. Secondly, the competitiveness of the furniture industry in the three regions of China is changing while the spatial difference of Chinese furniture industry decreasing. The competitiveness of furniture industry in eastern region has declined; that of the central region is related to the development of regional furniture market; and that of the western region is proportional to the added value of the secondary industry and foreign investment. Thirdly, we should strengthen the construction of cross-regional furniture industry chain, increase the investment in furniture design and the manufacturing technology in eastern region, focus on the development of regional furniture markets in central region, and develop the correlative industry and provide financial support for furniture enterprises in the west.

\subsection{Future Research Directions}

This paper only analyzed the spatial difference of the furniture industry of the East, the Central and the West regions of the China, but it did not study that of the provincial areas or smaller spatial scale regions. Narrowing the spatial scale of the study may obtain more accurate conclusions. In the future, the focus of the study will be smaller to reveal more precise sustainable development strategies. In addition, furniture can be divided into wooden furniture, bamboo and rattan furniture, steel furniture, plastic furniture and other type of furniture, etc. Because of each type of furniture has specific spatial characteristics, we will study in categories to reveal the spatial characteristic of each type of furniture industry and put forward more precise sustainable development strategies in China. The key to the researches will be the complete and accurate data of each type of furniture manufacture in smaller spatial scales.

\section{Acknowledgements}

This research is supported by the project of philosophy and social science research in colleges and universities in Jiangsu province (No. 2016SJB840022). 


\section{References}

Bryson, V., Lanzillotti, G., Myerberg, J. et al. (2003). The Furniture Industry (Case Goods): The Future of the Industry, United States versus China. Unpublished Manuscript, Chapel Hill, NC: University of North Carolina Kenan-Flagler Business School.

Chen, P. Y. (2015). Research on the Development Potential of China's Furniture Industry. Productivity Research, 7, 56-60. (In Chinese)

Cheng, Y., Jiang, Y. C., \& Zhang, S. B. (2014). The Situation and Sustainable Development Strategy of Chinese Furniture Industry. Wood Processing Machinery, 5, 58-60. (In Chinese)

Cheng, B. D. (2011). Competitiveness Analysis of Furniture Industry Cluster in Guangdong Province Based on GEM Model. Journal of Beijing Forestry University (Social Sciences), 10, 76-79. (In Chinese)

Feng, Q. L., Cheng, B. D., \& Hao, H. C. (2011). Empirical Study on Regional Economic Competitiveness of China's Wood Furniture Industry. Journal of Beijing Forestry University (Social Sciences), 10, 72-75. (In Chinese)

Gordan, D., \& Martina, B. S. (2015). A Roadmap of Actions Aiming at Ensuring Furniture Industry Production Growth: Panel Analysis. Economic Research Ekonomska IstraŽivanja, 28, 572-582. https://doi.org/10.1080/1331677X.2015.1083458

Grzegorzewska, E., \& Wieckowska, M. (2016). Selected Aspects of Innovation in the Furniture Industry-Empirical Research Findings. Drewno, 59, 148-161.

Li, F. (2015). The Measurement of Transferring Effect and Influencing Factors of China Furniture Industry to Midwest. Journal of Chongqing University of Arts and Sciences (Social Sciences Edition), 34, 105-110. (In Chinese)

Lin, W. M., Dai, Y. W., \& Yu, J. H. (2014). An Empirical Study on the Factors Influencing the International Competitiveness of Wooden Furniture Industry. Southeast Academic Research, 6, 135-143. (In Chinese)

Qin, Z. Q., \& Zhao, S. L. (2010). Evolution of Governance Structure of Dongguan Furniture Industry Cluster under the Global Industry Chain. Modern Management Science, 2, 76-77. (In Chinese)

Sang, H. L., Zhang, B., \& Tian, G. S. (2016). Dynamic Development Analysis of the Furniture Industry in Heilongjiang Province, China from the Perspective of Wood Processing and Furniture Import and Export. International Journal of $u$ - and e-Service, 9, 385-396.

Shen, H. J., Qiu, J. \& Liu, H. (2016). Some Views on Developing Furniture Industry in Yunnan under the Background of INTERNET Plus. In 2nd Annual International Conference on Social Science and Contemporary Humanity Development (pp. 548-554). Atlantis Press.

Tian, G. (2006). China Furniture Industry: Its Relative Advantages and "Outgoing” Strategy. Forestry Economics, 5, 30-33. (In Chinese)

Wang, B., Zhang, C. X., \& Qiu, J. (2011). Key Factors of International Competitiveness of Wood Furniture Industry. Journal of Fujian Agriculture and Forestry University (Philosophy and Social Sciences), 14, 43-48. (In Chinese)

Wang, X. (2001). The Research of Furniture Industry Model and Sustainable Development in Pearl River Delta. China Population, Resources and Environment, 11, 154-155. (In Chinese)

$\mathrm{Xu}, \mathrm{B} . \mathrm{M}$. (2016). The Structure and Form in the Furniture Manufacturing Industry in China in the Future. Furniture \& Interior Design, 1, 16-19. (In Chinese) 
Zeng, J. J., \& Nie, Y. (2012). Panel Data Identification of Convergent and Divergent Power in Regional Furniture Industry Cluster: Empirical Analysis on Second Natural Factor. World Forestry Research, 25, 51-56. (In Chinese)

Zeng, J. J., Ma, L. J, \& Yang, L. J. (2015). Deviation and Competition: Chinese Furniture Industry Spatial Differentiation. Journal of Agro-Forestry Economics and Management, 14, 398-403. (In Chinese)

Zeng, J. J., \& Nie, Y. (2015). A Study on Regional Difference and Evolutional Path of Labor-Intensive Industries in China: Furniture Industry as a Case. Asia-Pacific Economic Review, 4, 104-109. (In Chinese) 


\section{Appendix}

1) The Theil index, the variation coefficient of China's furniture industry from 2003 to 2012.

\begin{tabular}{lcccccccc}
\hline \multirow{2}{*}{ Time } & \multirow{2}{*}{$\begin{array}{c}\text { The } \\
\text { variation } \\
\end{array}$} & \multicolumn{9}{c}{ The Theil index } \\
\cline { 3 - 9 } & coefficient & East & Middle & West & inter-regional & national & \multicolumn{2}{c}{ inter-regionalIntra-regional } \\
\hline 2003 & 2.4603 & 0.2278 & 0.1322 & 0.2904 & 0.1396 & 0.3523 & 39.6253 & 60.3747 \\
2004 & 2.7662 & 0.2449 & 0.1283 & 0.2399 & 0.1484 & 0.3687 & 40.2495 & 59.7505 \\
2005 & 2.6960 & 0.2194 & 0.1094 & 0.1728 & 0.1452 & 0.3265 & 44.4717 & 55.5283 \\
2006 & 2.3294 & 0.1847 & 0.1742 & 0.1973 & 0.1328 & 0.2872 & 46.2396 & 53.7604 \\
2007 & 2.3449 & 0.1971 & 0.1825 & 0.2103 & 0.1270 & 0.3237 & 39.2339 & 60.7661 \\
2008 & 2.3234 & 0.2109 & 0.1881 & 0.2062 & 0.1219 & 0.3120 & 39.0705 & 60.9295 \\
2009 & 2.1662 & 0.1690 & 0.1672 & 0.2092 & 0.1172 & 0.2624 & 44.6646 & 55.3354 \\
2010 & 2.0360 & 0.1527 & 0.1817 & 0.2117 & 0.1156 & 0.2413 & 47.9072 & 52.0928 \\
2011 & 2.0536 & 0.1720 & 0.2133 & 0.2201 & 0.1048 & 0.2457 & 42.6536 & 57.3464 \\
2012 & 2.0265 & 0.1907 & 0.1991 & 0.1756 & 0.0971 & 0.2539 & 38.2434 & 61.7566 \\
\hline
\end{tabular}

2) The correlation analysis of furniture exports and variation coefficient from 2003 to 2012.

The Pearson correlation coefficient: -0.856

\begin{tabular}{clcc}
\hline & & The variation coefficient & Furniture exports \\
\hline \multirow{2}{*}{ The variation coefficient } & Pearson & 1 & $-0.856^{* *}$ \\
& number & 10 & 10 \\
\multirow{2}{*}{ furniture exports } & Pearson & $-0.856^{* *}$ & 1 \\
& number & 10 & 10 \\
\hline
\end{tabular}

The Spearman correlation coefficient: -0.927

\begin{tabular}{cccc}
\hline & & The variation coefficient & Furniture exports \\
\hline \multirow{2}{*}{ The variation coefficient } & Spearman & 1 & $-0.927^{* *}$ \\
& number & 10 & 10 \\
furniture exports & Spearman & $-0.927^{\star *}$ & 1 \\
& number & 10 & 10 \\
\hline
\end{tabular}

3) The correlation analysis of furniture exports and The Theil index from 2003 to 2012

The Pearson correlation coefficient: -0.841

\begin{tabular}{cccc}
\hline & & The variation coefficient & Furniture exports \\
\hline \multirow{2}{*}{ The variation coefficient } & Pearson & 1 & $-0.841^{* *}$ \\
& number & 10 & 10 \\
\multirow{2}{*}{ furniture exports } & Pearson & $-0.841^{* *}$ & 1 \\
& number & 10 & 10 \\
\hline
\end{tabular}


The Spearman correlation coefficient: -0.879

\begin{tabular}{cccc}
\hline & & The variation coefficient & furniture exports \\
\hline \multirow{2}{*}{ The variation coefficient } & Spearman & 1 & $-0.879^{* *}$ \\
& number & 10 & 10 \\
\multirow{2}{*}{ furniture exports } & Spearman & $-0.879^{* *}$ & 1 \\
& number & 10 & 10 \\
\hline
\end{tabular}

